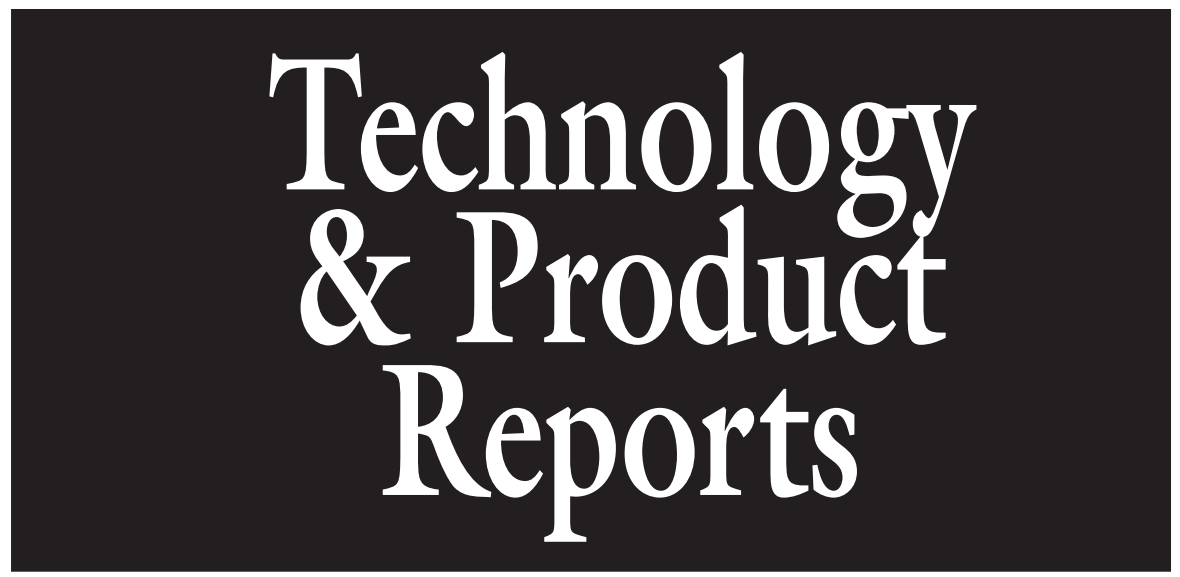

\section{Rapid Estimation of Citrus Tree Damage from Hurricanes in Florida Using an Ultrasonic Tree Measurement System}

\author{
Q.U. Zaman, A.W. Schumann ${ }^{1}$, and H.K. Hostler
}

ADDITIONAL INDEX WORDS. canopy volume, geographic information system, GIS, global positioning system, GPS, missing trees, sensor

SumMary. Many citrus groves in Florida were affected by hurricanes in Summer 2004. A commercial 42-acre 'Valencia' sweet orange (Citrus sinensis) grove of 2980 trees was routinely scanned with an automated ultrasonic system to measure and map tree canopy volumes. We estimated tree damage by comparing canopy volumes measured before and after the hurricanes of 2004. Ultrasonically sensed tree canopy volume was mapped and the relative tree canopy volume loss percentage (TCVL\%) for each tree was calculated and classified into six categories [ $\leq 0$ (no damage), $1 \%$ to $24 \%, 25 \%$ to $49 \%, 50 \%$ to $74 \%, 75 \%$ to $99 \%$, and $100 \%$ ]. Authenticity of the ultrasonically sensed missing trees was established by ground truthing or matching visually observed and georeferenced missing tree locations with ultrasonically sensed missing trees in the grove. Ninety-one trees were found missing during ground inspections after hurricanes and they exactly matched with ultrasonically sensed missing tree locations throughout the grove. All of the missing trees were in TCVL\% categories 5 and 6 ( $\geq 75 \%$ damage). Some canopy volume was still detected with ultrasonics at the missing tree locations because of the presence of tall grass, weeds, or branches of large adjacent trees. More than $50 \%$ of trees in the grove were damaged (completely or partially) and generally larger trees $\left(>100 \mathrm{~m}^{3}\right)$ were damaged more by the hurricanes than small or medium size trees in each tree canopy volume loss category. The automated ultrasonic system could be used to rapidly identify missing trees (completely damaged) and to estimate partial tree canopy volume loss after hurricanes.

$\mathrm{T}$ The Florida citrus industry has a $\$ 9.1$ billion economic impact, employs nearly 90,000 people and covers 750,335 acres (Florida
Agricultural Statistics Service, 2003). Four hurricanes in the summer of 2004 affected most Florida citrus growers. The loss from these hurricanes in- cluded damage to infrastructure, tree canopy damage, fruit dropped from trees, and also increased spread of the citrus canker (Xanthomonasaxonopodis pv. citri) disease. The hurricanes also damaged or destroyed grove pumps, power units, and other equipment. Measurement of loss in tree canopy volume after hurricanes may be valuable for crop insurance and fruit yield estimation. Data for tree canopy volume after hurricanes may also be useful to produce prescription maps for accurate site-specific fertilization on a per-tree basis to improve horticultural profitability and eliminate prolonged nitrate excesses in the root zone, which can potentially leach to groundwater (Zaman et al., 2005).

The visual/manual estimation of the tree damage in each grove is laborious, time consuming, and difficult to quantify. Tree canopy size could be determined from aerial photography (Whitney et al., 1999). However, obtaining up-to-date aerial photography is expensive and the freely available Land Boundary Information System (LABINS) aerial photographs of Florida citrus groves on the Internet are updated infrequently, at a 4-year interval (Florida Department of Environmental Protection, 1999). One possible method to estimate tree damage is ultrasonic sensor-based tree location and canopy volume measurements. Ultrasonic sensors have been successfully demonstrated for the quantification of tree canopy volume (Giles et al., 1988; Roper, 1988; Tumbo et al., 2002; Zaman and Salyani, 2004). Schumann and Zaman (2005) developed and evaluated a Windows-based software application for an ultrasonic tree size measurement system using a differentially corrected geographic positioning system (DGPS) that allowed automated real-time sensing, monitoring, calculation, storage and mapping of citrus tree location, and canopy volume and height rapidly and reliably. This information could be readily used to estimate tree damage from freezes, disease, and hurricanes within the groves. Zaman and Schumann (2005)
Soil and Water Science Department, University of Florida, IFAS, Citrus Research and Education Center, 700 Experiment Station Road, Lake Alfred, FL 33850 .

This research was supported by the Florida Agricultural Experiment Station and FCPRAC grant no. 032-02M Implementation of Precision Agriculture Technology to Improve Profitability of Florida Citrus, approved as Journal Series No. R-11061. The authors would also like to thank John Strang and David Anglin for their assistance during the experiment. Mention of products is for information purposes only and does not imply an endorsement by the University of Florida over products not mentioned.

${ }^{1}$ To whom reprint requests should be addressed; e-mail: schumaw@ufl.edu

\begin{tabular}{lllc}
\hline $\begin{array}{l}\text { Units } \\
\begin{array}{l}\text { To convert U.S. to SI, } \\
\text { multiply by }\end{array}\end{array}$ & U.S. unit & SI unit & $\begin{array}{l}\text { To convert SI to U.S., } \\
\text { multiply by }\end{array}$ \\
\hline 0.4047 & $\mathrm{acre}(\mathrm{s})$ & $\mathrm{ha}$ & 2.4711 \\
0.3048 & $\mathrm{ft}$ & $\mathrm{m}$ & 3.2808 \\
0.0283 & $\mathrm{ft}^{3}$ & $\mathrm{~m}^{3}$ & 35.3147 \\
1.1209 & $\mathrm{lb} / \mathrm{acre}$ & $\mathrm{kg} \cdot \mathrm{ha}^{-1}$ & 0.8922 \\
1.6093 & $\mathrm{mph}$ & $\mathrm{km} \cdot \mathrm{h}^{-1}$ & 0.6214
\end{tabular}


validated the accuracy of the ultrasonic measurement system in four different citrus groves where varying degrees of canopy damage had occurred from diseases and freezes. The ultrasonic system measured tree volumes reliably in these different groves with an average prediction accuracy (APA) $>90 \%$, and correlation with manual measurement of $\mathrm{R}^{2}=0.95-0.99$. Therefore, the objective of this study was to use this ultrasonic measurement system to identify missing trees (completely damaged and removed trees) and assess the tree canopy volume loss (partially damaged trees) from hurricanes within citrus groves.

\section{Materials and methods}

Grove history. A commercial citrus grove near Fort Meade, Polk County, Fla. (lat. $27.74789^{\circ} \mathrm{N}$, long. $81.69509^{\circ} \mathrm{W}$ ) was selected for tree location and canopy volume measurements in 2003 (before the hurricanes) and 2004 (after the hurricanes). The 42 -acre grove was planted with $>40$ year-old 'Valencia' sweet orange trees on Carrizo citrange (Poncirus trifoliate $\times$ C. sinensis) rootstock. Tree row orientation was north-south with a tree spacing of $35.0 \mathrm{ft}$ between rows and $17.5 \mathrm{ft}$ within the rows. The tree canopies were not topped or hedged at the time of measurement. The soil type in the grove was Candler sand (hyperthermic, coated Typic Quartzipsamments). There was large spatial variability in tree canopy sizes because of a wide range of tree ages. Many original trees had been replaced due to tree loss from hurricanes, freezes, and disease (J. Strang, personal communication). Ground inspections in Sept. 2004 revealed that trees were damaged from the 2004 hurricanes and gaps between adjacent trees were also found at some places where trees had been severely damaged and removed from the grove.

Hurricane Data. The citrus grove in this study was strongly impacted by three hurricanes during Aug. and Sept. 2004. Most of the damage to trees was from wind gusts causing partial defoliation, fruit drop, broken branches, and some broken trunks. The completely destroyed trees and large broken branches were removed from the grove within 3 to 4 weeks because they obstructed vehicular traffic through the driving middles. Wind speeds were measured with a
WatchDog Model 900ET Weather Station (Spectrum Technologies, East Plainfield, Ill.) at $2.0 \mathrm{~m}$ above ground. The weather station was located 416 $\mathrm{m}$ southeast of the 'Valencia' sweet orange block in this study, in an adjacent immature 'Hamlin' sweet orange block where maximum tree height was $3.5 \mathrm{~m}$. The center track of Hurricane Charley, the first storm, passed within $6400 \mathrm{~m}$ of the grove on 13 Aug. 2004, with maximum measured wind speeds in the grove of $217 \mathrm{~km} \cdot \mathrm{h}^{-1}$ (Fig. 1A). Hurricane Charley was smaller in size, but faster moving and more powerful than Hurricane Frances and Hurricane Jeanne, the second and third storms. Most of the complete tree destruction occurred during Hurricane Charley. The center track of Hurricane Frances passed within $15,520 \mathrm{~m}$ of the grove on 5-6 Sept. 2004, with maximum measured wind speeds in the grove of $120 \mathrm{~km} \cdot \mathrm{h}^{-1}$ (Fig. 1B). The center track of Hurricane Jeanne passed within $3200 \mathrm{~m}$ of the grove on 26 Sept. 2004, with maximum measured wind speeds in the grove of $154 \mathrm{~km} \cdot \mathrm{h}^{-1}$ (Fig. IC). Hurricane Jeanne made the closest approach to the grove, with the eye of the hurricane clearly evident in the brief calm period during the morning of 26 Sept. (Fig. 1C).

ULTRASONICALLY SENSED TREE LOCATIONS AND VOLUME MEASUREMENTS. Two comprehensive surveys were conducted in June 2003 (before the hurricanes) and Sept. 2004 (after the hurricanes) to measure and map each tree location and canopy volume in the grove with an automated ultrasonic system (Durand-Wayland, Lagrange, Ga.). The system configuration used 10 ultrasonic transducers mounted at 0.6-m increments on a 0.1 -m-diameter vertical PVC mast. Transducer 1 was nominally $0.6 \mathrm{~m}$ above ground level, and transducer 10 was $6.0 \mathrm{~m}$ high. The mast was mounted on a custom trailer, which was hitched behind a fourwheel-drive pickup truck and driven midway between two rows of trees so that the mast was approximately on the centerline. In this configuration, each transducer measures the horizontal distance between the mast and the nearest peripheral foliage of the tree canopy. A Trimble AgGPS-132 DGPS antenna (Trimble Navigation Ltd., Sunnyvale, Calif.) was mounted at the mast between transducers 4 and 5 to collect horizontal position and ground speed data. The DGPS receiver was configured for a $\mathrm{l}-\mathrm{Hz}$ acquisition rate using U.S. Coast Guard (USCG) beacons for differential correction. Only one side of the trees was scanned and the result doubled, assuming approximate symmetry. Extensive research data from different citrus groves, including partially damaged trees of different sizes, demonstrated that one-sided measurement of tree canopies with the ultrasonic system was sufficiently accurate (Schumann and Zaman, 2005; Zaman and Schumann, 2005). An on-board microcontroller and custom transducer-triggering circuitry controlled the rate of data acquisition $(5.1 \mathrm{~Hz})$ from the 10 transducers. The total effective (return path) divergence angle of the ultrasonic pulse was about $12^{\circ}$ (Li et al., 2002) at an operating frequency of $40 \mathrm{kHz}$. The maximum measuring range of the ultrasonic transducers was $7.6 \mathrm{~m}$ (Tumbo et al., 2002), and data were digitized in 8-bit format $(0-255)$ so that 255 represented a distance of $7.6 \mathrm{~m}$. The resulting distance resolution of each transducer was therefore $0.03 \mathrm{~m}$. Data from the 10 ultrasonic transducers were transferred continuously to a $1.4-\mathrm{GHz}$ laptop computer in the pickup truck's cab through a RS232 communication cable $(9600,8, n, 1)$, routed through the DGPS. The DGPS position data were simultaneously transmitted (merged) to the same laptop RS232 port at $1 \mathrm{~Hz}$, using the National Marine Electronics Association (NMEA-0183) standard RMC sentence. In this study, the system was moved at an average ground speed of $1.3 \mathrm{~m} \cdot \mathrm{s}^{-1}$ to get vertical (10) and horizontal (17) samples per tree space, which were deemed adequate to accurately depict canopy volume $(\mathrm{Li}$ et al., 2002; Schumann and Zaman, 2005). The technical design of the system (hardware and software) and detailed procedure for the real-time measurement and mapping of tree volume in a grove were reported earlier (Schumann and Zaman, 2005).

VISUALLY OBSERVED (GROUNDTRUTH) MISSING TREE LOCATIONS. The missing (completely damaged and removed) trees were located in the grove after the hurricanes with the Trimble AgGPS132 DGPS using USCG beacon correction and Fugawi moving map software (Northport Systems, Toronto) on a laptop computer.

Data Analysis. The survey data files of ground-truth missing tree positions and ultrasonically sensed tree 

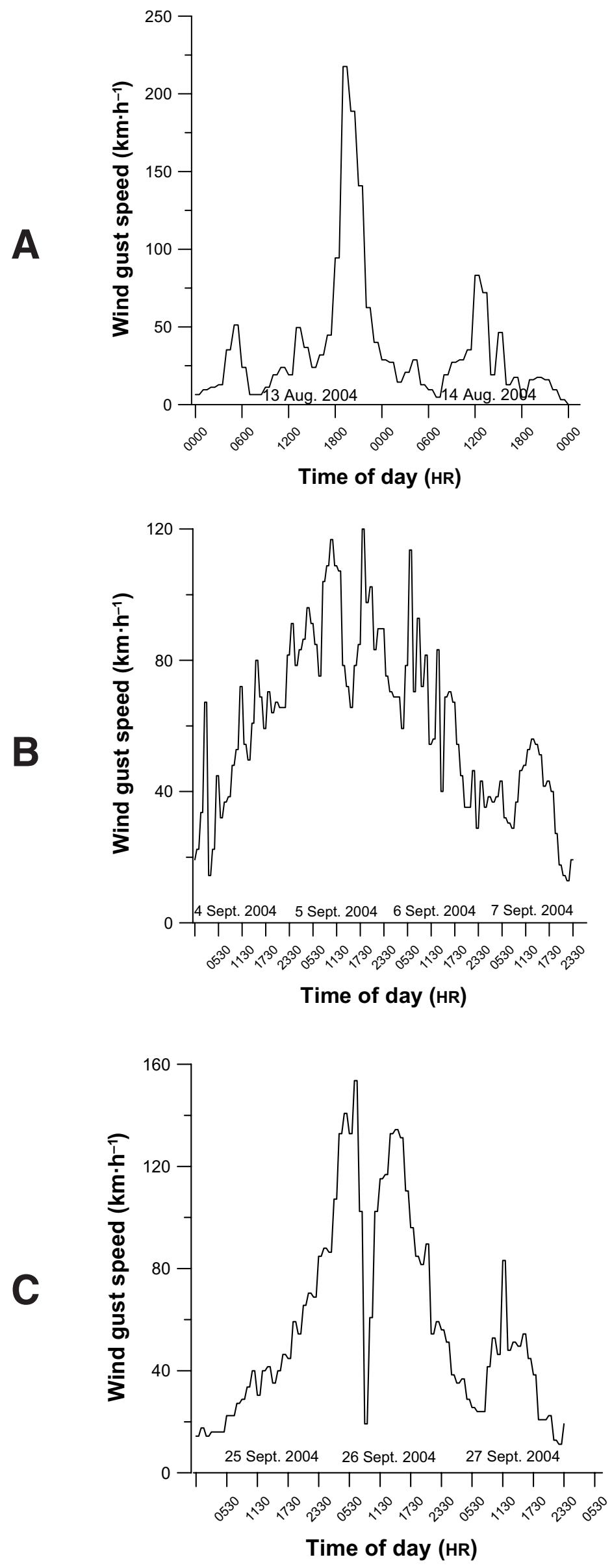

Fig. 1 (left). Wind gust speed measured in the 'Valencia' sweet orange grove during (A, top) Hurricane Charley, (B, middle) Hurricane Frances, and $(\mathrm{C}$, bottom) Hurricane Jeanne (1 $\left.\mathrm{km} \cdot \mathrm{h}^{-1}=0.6214 \mathrm{mph}\right)$.

canopy volumes were imported into ArcView 3.2 GIS software (ESRI, Redlands, Calif.) to map each tree canopy volume before and after hurricanes for tree damage comparison. The tree volume loss percentage was computed using the following formula:

$$
\operatorname{TCVL}(\%)=\frac{T C V_{2003}-T C V_{2004}}{T C V_{2003}} \times 100
$$

where TCVL $=$ ultrasonically sensed tree canopy volume loss percentage; $\mathrm{TCV}_{2003}$ and $\mathrm{TCV}_{2004}$ are the ultrasonically sensed canopy volumes in 2003 (before hurricanes) and in 2004 (after hurricanes), respectively.

The TCVL\% was classified into six categories: category (TCVL\%) 1 $(\leq 0), 2(1-24), 3(25-49), 4(50-74)$, $5(75-99)$, and $6(100)$, where $\leq 0 \%=$ no tree damage, $100 \%=$ completely damaged and removed.

The ground-truth missing tree locations were superimposed on the $\mathrm{TCV}_{2004}$ map for comparison. Tree volume loss data were analyzed to produce a frequency histogram distribution of TCVL in the entire grove with SAS software (SAS Institute, Cary, N.C.). Percentage of total trees in each tree volume loss category for different tree size classes were also calculated and presented graphically using SigmaPlot 8.0 (SPSS Inc., Chicago).

\section{Results and discussion}

Canopy volumes of the 2980 trees were measured and georeferenced with ultrasonic sensors at a mean speed of $1.3 \mathrm{~m} \cdot \mathrm{s}^{-1}$, taking $4 \mathrm{~h}$ to complete the survey of 42 acres before and after the hurricanes. The $\mathrm{TCV}_{2003}$ in this grove ranged from 0 (missing) to $240 \mathrm{~m}^{3}$ (Fig. 2A), due to the age of the grove ( $>40$ years), and the practice of continuous replanting (resetting) of dead, damaged, or diseased trees (J. Strang, personal communication). However, after the hurricanes, more missing and partially damaged trees were observed throughout the grove (Fig. 2B).

The ground-truth missing tree location map showed that 91 trees were removed from the grove after hurricanes and were scattered throughout the grove (Fig. $2 \mathrm{~B}$ ). The $\mathrm{TCV}_{2003}$ map 


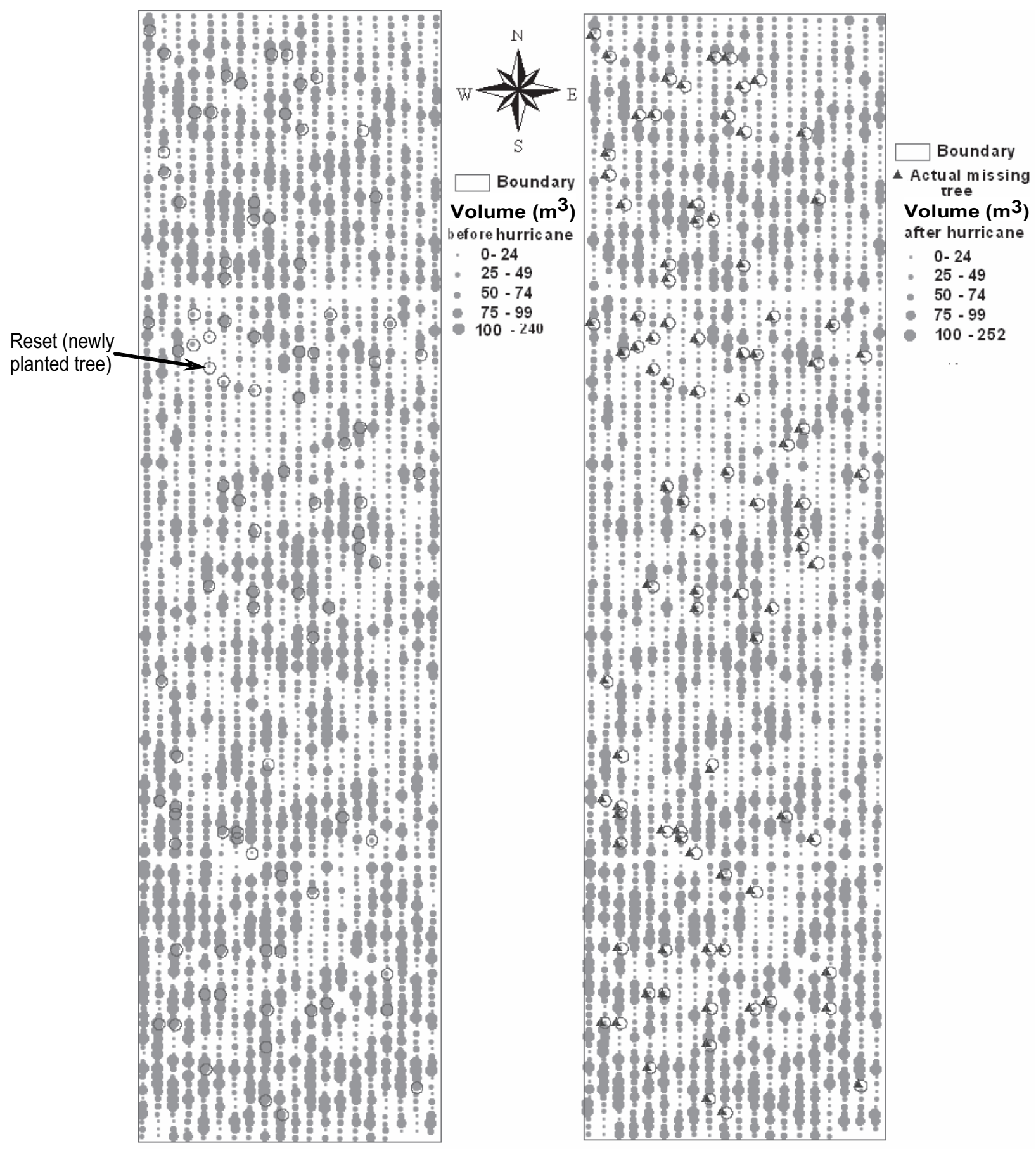

A.

B.

Fig. 2. Ultrasonically sensed 'Valencia' sweet orange tree canopy volumes (A, above left) in 2003 before hurricanes and (B, above right) in 2004 after hurricanes. Missing trees detected by ultrasonics are indicated by circles. Some canopy volume was erroneously detected by ultrasonic sensors due to the presence of weeds or branches of adjacent large trees at some missing tree locations. Visually observed missing tree locations $(\Delta)$ are superimposed on the 2004 ultrasonically sensed tree volume map for ground truthing $\left(1 \mathrm{~m}^{3}=35.3147 \mathrm{ft}^{3}\right)$.

indicated large tree canopy volumes at the place of missing trees (Fig. 2A, circled trees), while $\mathrm{TCV}_{2004}$ showed no volume or very small volume at the missing tree locations (Fig. 2B, circled trees). The ground-truth missing trees were compared with the ultrasonically sensed missing tree data. The groundtruth missing tree locations superimposed on the $\mathrm{TCV}_{2004}$ map illustrates that actual and ultrasonically sensed missing tree locations in the grove coincided exactly with each other (Fig. 2B). All (9l) missing trees were in
TCVL (\%) categories 5 (75\% to $99 \%$ TCVL) and 6 (100\% TCVL), indicating that ultrasonic sensors detected zero or negligible tree volume at the locations of missing trees (Figs. 2B and 3 ). Ground inspections revealed that ultrasonic sensors sometimes detected 
small volumes because of presence of tall grass, weeds, or branches of large adjacent trees at some missing tree locations in the grove. In addition to missing trees (3\% of the total trees), the frequency distribution analysis of TCVL showed 46 (1.6\% of the total trees) more trees were highly damaged (75\% to $99 \%$ TCVL) and needed to be removed from the grove (Fig. 3). The $\mathrm{TCV}_{2004}$ and $\mathrm{TCV}_{2003}$ maps clearly showed that the partially damaged trees were larger in size before hurricanes and smaller in size after hurricanes (Fig. 2A-B). An amount of $10.4 \%$ of the total trees appeared to have more than $50 \%$ canopy damage and $17 \%$ of trees were partially damaged and lost $25 \%$ to $49 \%$ of their total tree canopy volume (Fig. 3). Results of this study indicated that $29 \%$ of trees incurred minor canopy damage ( $1 \%$ to $24 \%$ TCVL) and $43 \%$ of trees (category 1 ) were not affected by the hurricanes in the grove (Fig. 3 ) and showed larger or the same volumes in the $\mathrm{TCV}_{2004}$ map than the volumes in the $\mathrm{TCV}_{2003}$ map (Fig. 2A-B). It would appear the ultrasonic system is very useful and reliable for quick estimation of TCVL after hurricanes.

More than $80 \%$ of the most severely damaged trees in category 6 and $70 \%$ of the trees in category 5 were large in size (volume $>100 \mathrm{~m}^{3}$ ), and were removed from the grove (Fig. $4)$. The larger size trees were more damaged than small or medium size trees in all categories of TCVL, and therefore the largest tree category was responsible for most changes to the variable rate fertilizer prescription map of the grove after the 2004 hurricanes. We saved $38 \%$ and $40 \%$ fertilizer before and after hurricanes, respectively, with variable rate application (VRA) of fertilizer in the western half of the grove as compared to the grower's uniform nitrogen rate of $240 \mathrm{lb} /$ acre per year in the eastern half of the same grove (Zaman et al., 2005). These additional $2 \%$ fertilizer savings with VRA after the hurricanes did not correspond exactly to the $15 \%$ reduction of TCV in the whole grove from $237,229 \mathrm{~m}^{3}$ in 2003 to $201,104 \mathrm{~m}^{3}$ in 2004 . The discrepancy was probably due to the VRA fertilization only being implemented in half of the grove, and because the six fertilizer rates were allocated according to six canopy size classes. Most of the damage was also confined to the larger

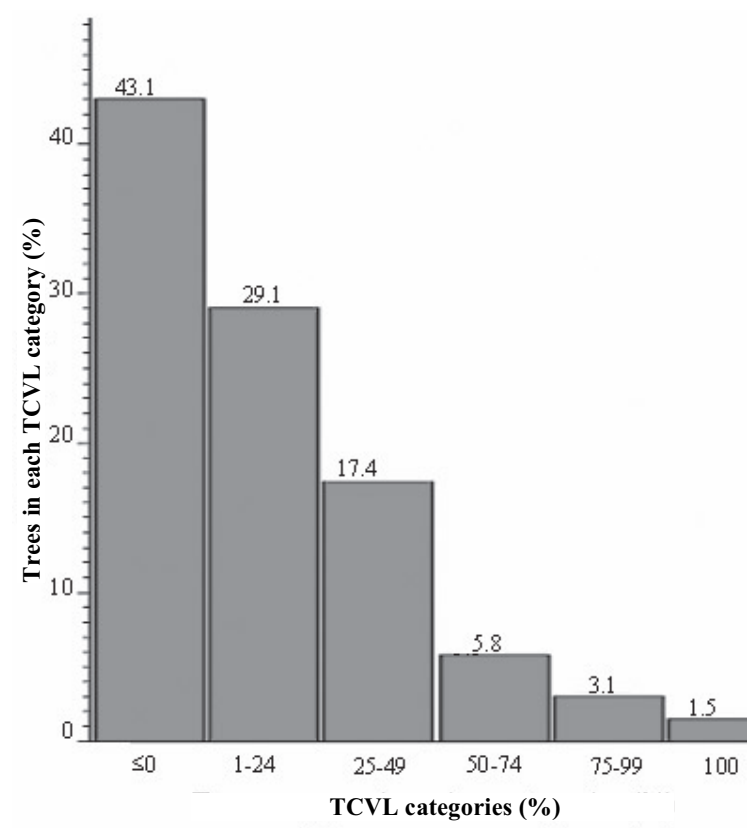

Fig. 3. Frequency distribution (\%) of 'Valencia' sweet orange tree canopy volume loss [TCVL (\%)] determined with ultrasonic sensors for the 2980 trees in the grove.

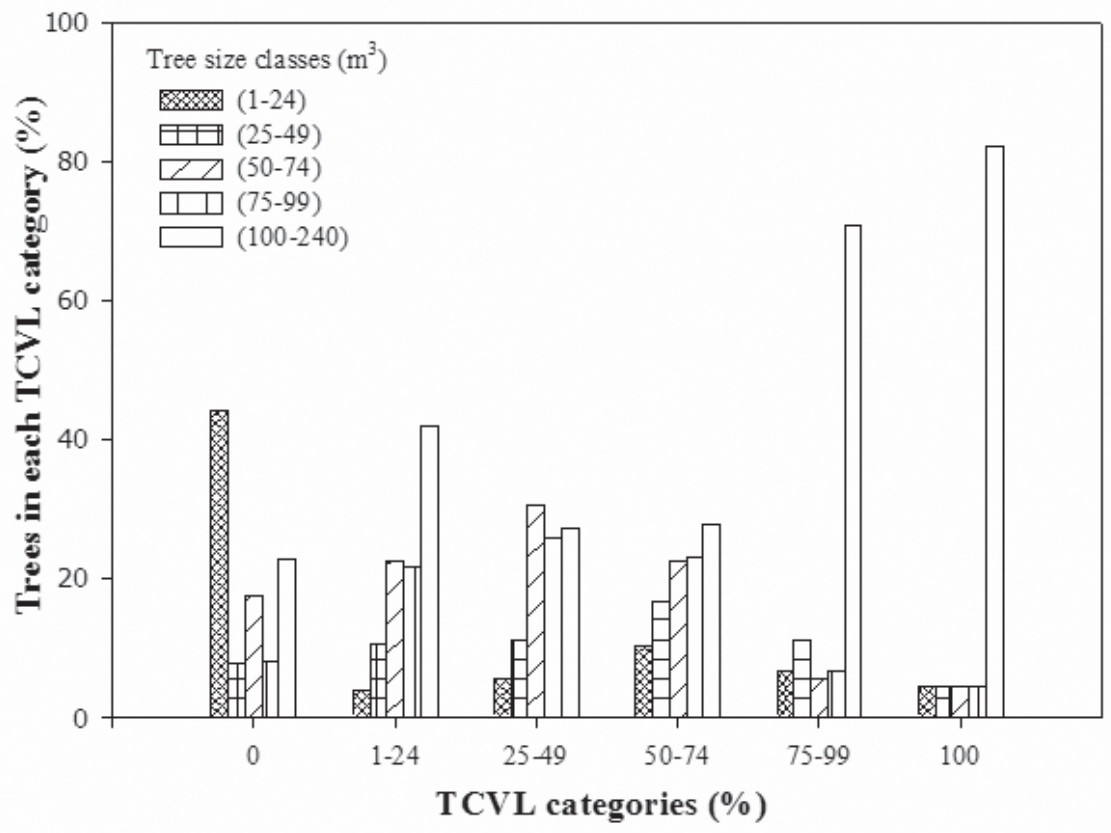

Fig. 4. Frequency distribution (\%) of 'Valencia' sweet orange tree canopy volume loss $[$ TCVL $(\%)]$ for each tree size class $\left[\mathrm{m}^{3}\left(1 \mathrm{~m}^{3}=35.3147 \mathrm{ft}^{3}\right)\right]$.

trees, and therefore one or two fertilizer rates were mainly affected. Therefore, it is important to measure and map tree size in real-time with an automated ultrasonic system after hurricanes for a quick up-to-date estimation of trees damaged. However, the one-sided ultrasonic tree canopy volume measurement technique relies on symmetrical canopy shape, which may cause large errors if hurricane damage removes only half of the canopy.

\section{Conclusions}

An automated ultrasonic sensor system with DGPS can measure and map tree loss (complete and partial tree damage) from hurricanes. This ultra- 
sonic system performed well to identify missing trees and to estimate the tree volume loss of partially damaged trees from hurricanes. The ultrasonically sensed missing tree data is useful for both inventory and planning to replant the trees at the places of mature missing trees. The ultrasonic tree canopy volume loss information after hurricanes would also be valuable to generate prescription maps for accurate sitespecific fertilization to assist canopy growth in the groves. The single-sided ultrasonic measurement system could detect major structural canopy damage due to broken branches and trunks. We can conclude that the accuracy of this ultrasonic measurement would be further improved if both sides of the trees were measured to avoid errors from asymmetrical trees, but that this would take twice the time.

\section{Literature cited}

Florida Agricultural Statistics Service. 2003. Commercial citrus inventory. Fla. Agr. Stat. Serv., Orlando.

Florida Department of Environmental Protection. 1999. Land boundary information system-Aerial photograph for Florida citrus. 20 July 2005. <http://data.labins. org/2003/MappingData/DOQQ/ doqq_99_utm.cfm>.

Giles, D.K., M.J. Delwiche, and R.B. Dodd. 1988. Electronic measurement of tree canopy volume. Trans. Amer. Soc. Agr. Eng. 31(1):264-272.
Li, B., J.D. Whitney, W.M. Miller, and T.A. Wheaton. 2002. Ultrasonic-based canopy volume measurements of citrus trees for precision agriculture. Amer. Soc. Agr. Eng. Paper No. 02021053. ASAE, St. Joseph, Mich.

Roper, B.E. 1988. Grove sprayer. U.S. Patent No. 4768713. U.S. Patent and Trademark Office, Washington, D.C.

Schumann A.W. and Q.U. Zaman. 2005. Software development for real-time ultrasonic mapping of tree canopy size. Computer Electronics Agr. 47(1):25-40.

Tumbo, S.D., M. Salyani, J.D. Whitney, T.A. Wheaton, and W.M. Miller. 2002. Investigation of laser and ultrasonic ranging sensors for measurement of citrus canopy volume. Appl. Eng. Agr. 18(3):367-372.

Whitney, J. D., W.M. Miller, T.A. Wheaton, M. Salyani, and J.K. Schueller. 1999. Precision farming applications in Florida citrus. Appl. Eng. Agr. 15(5):399-403.

Zaman, Q.U. and M. Salyani. 2004. Effects of foliage density and ground speed on ultrasonic measurements of tree volume. Appl. Eng. Agr. 20(2):173-178.

Zaman, Q.U. and A.W. Schumann. 2005. Performance of an ultrasonic tree volume measurement system in commercial citrus groves. Precision Agr. 6(5):467-480.

Zaman, Q.U., A.W. Schumann, and W.M. Miller. 2005. Variable rate nitrogen application in Florida citrus based on ultrasonically-sensed tree size. Appl. Eng. Agr. 21(3):331-335. 